\title{
Glutathione and abscisic acid supplementation influences somatic embryo maturation and hormone endogenous levels during somatic embryogenesis in Podocarpus lambertii Klotzsch ex Endl.
}

\author{
Hugo Pacheco de Freitas Fraga ${ }^{a}$, Leila do Nascimento Vieira ${ }^{a}$, \\ Catarina Corrêa Puttkammer ${ }^{\mathrm{a}}$, Henrique Pessoa dos Santos ${ }^{\mathrm{b}}$, Julio de Andrade Garighan ${ }^{\mathrm{b}}$, \\ Miguel Pedro Guerra ${ }^{a, *}$ \\ a Laboratório de Fisiologia do Desenvolvimento e Genética Vegetal, Centro de Ciências Agrárias, Universidade Federal de Santa Catarina, Florianópolis, SC, \\ 88034-001, Brazil \\ b Laboratório de Fisiologia Vegetal, Empresa Brasileira de Pesquisa Agropecuária, Embrapa Uva e Vinho, Bento Gonçalves, RS, 95700-000, Brazil
}

\section{A R T I C L E I N F O}

\section{Article history:}

Received 3 July 2016

Received in revised form

22 September 2016

Accepted 24 September 2016

Available online 28 September 2016

\section{Keywords:}

Brazilian conifer

Micropropagation

In vitro culture

Redox metabolism

Embryonic development

\begin{abstract}
A B S T R A C T
Here we propose a protocol for embryogenic cultures induction, proliferation and maturation for the Brazilian conifer Podocarpus lambertii, and investigated the effect of abscisic acid (ABA) and glutathione (GSH) supplementation on the maturation phase. ABA, zeatin (Z) and salicylic acid (SA) endogenous levels were quantified. Number of somatic embryos obtained in ABA-supplemented treatment was significant higher than in ABA-free treatment, showing the relevance of ABA supplementation during somatic embryos maturation. Histological analysis showed the stereotyped sequence of developmental stages in conifer somatic embryos, reaching the late torpedo-staged embryo. GSH supplementation in maturation culture medium improved the somatic embryos number and morphological features. GSH $0 \mathrm{mM}$ and GSH $0.1 \mathrm{mM}$ treatments correlated with a decreased ABA endogenous level during maturation, while GSH 0.5 mM treatment showed constant levels. All treatments resulted in decreased Z endogenous levels, supporting the concept that cytokinins are important during the initial cell division but not for the later stages of embryo development. The lowest SA levels found in GSH $0.5 \mathrm{mM}$ treatment were coincident with early embryonic development, and this treatment resulted in the highest development of somatic embryos. Thus, a correlation between lower SA levels and improved somatic embryo formation can be hypothesized.
\end{abstract}

(C) 2016 Elsevier Ireland Ltd. All rights reserved.

\section{Introduction}

Conifers comprise about 650 species, divided into seven families: Araucariaceae, Cephalotaxaceae, Cupressaceae, Pinaceae, Podocarpaceae, Sciadopityaceae and Taxaceae. Some species of this group are the largest and oldest land organisms on the planet [1]. Among several families of existing conifers, Podocarpaceae stands out as the most diverse family, which contains 18 genera and 173 species and is represented by trees and shrubs used for timber and ornamental purposes, mainly distributed in Southern Hemisphere [2].

Podocarpus lambertii Klotzsch ex Endl. (Podocarpaceae) is native from South and Southeastern Brazil and restricted areas of

\footnotetext{
* Corresponding author.

E-mail address: miguel.guerra@ufsc.br (M.P. Guerra).
}

Northwestern Argentina, naturally occurring in the Atlantic Forest Biome [3], which is considered one of the 25 biodiversity hotspots of the world [4]. According to the IUCN (International Union for Conservation of Nature and Natural Resources - www.iucnredlist.org), $P$. lambertii is near threatened, with declining population. Biotechnological tools such as somatic embryogenesis (SE), have potential for clonal propagation and ex situ conservation of endangered plant species, especially conifers [5-7].

SE is the developmental reprogramming of somatic cells toward the embryogenic pathway, and forms the basis of cellular totipotency in higher plants [8]. SE involves dedifferentiation of a nonzygotic cell and subsequent redifferentiation, resulting on the long term in the production of all cell types characteristic of the mature plant. These features make SE an efficient model system for the study of morphological, physiological, molecular and biochemical aspects that occur during the initiation and development in higher plants $[8,9]$. 
SE is affected by many factors, such as genotype, culture medium composition, plant growth regulators, gelling agent, type of explant, stress, and light [10]. However, among all these factors, plant growth regulators appear to play the most crucial role in this morphogenetic route [11]. Different molecules play regulatory roles in stress signaling, which is essential for SE induction and control, including those with hormonal activity [12], such as abscisic acid (ABA), zeatin (Z), and salicylic acid (SA). Specifically, ABA is reported to influence some aspects of $S E$, particularly the phase of somatic embryo maturation, during which it regulates the synthesis and deposition of storage compounds, induces desiccation tolerance and generates somatic embryo dormancy or quiescence [13]. Hence, efforts must be made to obtain a deeper understanding of endogenous hormones as embryogenic potential inducers and regulators of plant embryonic development.

During the last decade, protocols for SE in conifers have undergone rapid and significant progress [14]. However, somatic embryo maturation still a challenging step toward efficient obtainment of uniform and consistent mature somatic embryos [15]. A picture is emerging that shows that optimal early-stage somatic embryo development occurs in the presence of a reducing environment while a shift to an oxidizing environment is required for late-stage development $[16,17]$.

Glutathione (GSH) is a thiol tripeptide formed by glutamic acid, cysteine and glycine ( $\mathcal{Y}$-glu-Cys-gly) that can be found in most eukaryotic and prokaryotic cells [18]. In several plant species, the influence of GSH on cell division and differentiation has been reported $[19,20]$. In Picea glauca SE GSH supplementation in the culture medium showed beneficial effects on quantity and morphological features of somatic embryos [19]. Similarly, Vieira et al. [21] reported an increased pro-embryos formation and development in Araucaria angustifolia embryogenic cultures subjected to maturation with GSH supplementation, with a strong relationship between GSH addition and nitric oxide levels.

This study provides new insights into SE maturation of $P$. lambertii under a reducing environment caused by GSH supplementation and its consequences in the endogenous hormone levels. Our original approach consists in evaluate the effects of ABA and GSH supplementation during $P$. lambertii somatic embryo development and maturation. GSH supplementation effects on ABA, Z and SA endogenous levels were also investigated. As a consequence, a protocol for embryogenic cultures induction, proliferation and maturation of this Brazilian native conifer is proposed for the first time. Here, we demonstrate remarkable differences in somatic embryos number obtained during maturation with different levels of ABA supplementation. GSH-supplemented treatments indicated improved number and more developed somatic embryos, compared to GSH-free treatment. GSH supplementation affected ABA endogenous levels during embryo maturation, and a correlation between lower SA levels and improved somatic embryo formation could be hypothesized.

\section{Materials and methods}

\subsection{Somatic embryogenesis induction and proliferation}

Immature seeds bearing early globular-staged zygotic embryos were collected in January 2014, from a P. lambertii open-pollinated natural population in Lages, Santa Catarina - Brazil (latitude $27^{\circ} 49^{\prime} 0^{\prime \prime}$, longitude $50^{\circ} 19^{\prime} 35^{\prime \prime}$, altitude $930 \mathrm{~m}$ ). The seeds were submitted to disinfestation procedures with $70 \%$ ethanol for $1 \mathrm{~min}$ and sodium hypochlorite $1.5 \%(\mathrm{v} / \mathrm{v})$ for $15 \mathrm{~min}$, followed by a triplewashed with autoclaved distilled water. Zygotic embryos were excised from seeds and inoculated in Petri dishes containing $25 \mathrm{ml}$ of induction culture medium, sealed with PVC-film.
The induction culture medium consisted of MSG macro- and micro-salts [22] supplemented with BM vitamins [23], L-glutamine $\left(1.46 \mathrm{gl}^{-1}\right)$, myo-inositol $\left(0.1 \mathrm{gl}^{-1}\right)$, Phytagel ${ }^{\circledR}\left(2 \mathrm{gl}^{-1}\right)$ and sucrose $\left(30 \mathrm{gl}^{-1}\right)$. The $\mathrm{pH}$ of culture medium was adjusted to 5.8 and autoclaved at $121^{\circ} \mathrm{C}, 1.5 \mathrm{~atm}$ for $15 \mathrm{~min}$. All the cultures were maintained in a growth room in the absence of light at temperature of $22 \pm 2{ }^{\circ} \mathrm{C}$.

After 30 days induction, the embryogenic cultures (EC) were subcultured in Petri dishes containing $25 \mathrm{ml}$ of the same culture medium composition described for EC induction. Subcultures were made every 15 days for 4 cycles in gelled culture medium for the EC scale-up. Subsequently EC were transferred for proliferation in liquid culture medium (cell suspension) with the same composition as described above, without the gelling agent. The cell suspension was established with $500 \mathrm{mg}$ of EC in $250 \mathrm{ml}$ Erlenmeyer flasks containing $50 \mathrm{ml}$ of liquid culture medium, kept in dark conditions with permanent agitation $(90 \mathrm{rpm})$ in orbital shaker at temperature of $22 \pm 2{ }^{\circ} \mathrm{C}$. Subcultures were also made every 15 days for 4 cycles to EC scale-up.

\subsection{ABA supplementation experiments during maturation phase II}

The EC maintained in proliferation cycles in cell suspension were used in different maturation treatments in order to evaluate the ABA optimal concentration for $P$. lambertii somatic embryos obtainment. About $100-200 \mathrm{mg}$ FW of EC suspended in $2 \mathrm{ml}$ of proliferation culture medium was pippeted over a $70-\mathrm{mm}$ diameter filter paper disk in a Büchner funnel. The drained and dispersed EC was then cultured on 90-mm diameter Petri dishes containing $25 \mathrm{ml}$ of maturation phase I (MPI) culture medium. This culture medium consisted of MSG macro- and micro-salts supplemented with BM vitamins, L-glutamine $\left(1.46 \mathrm{~g} \mathrm{l}^{-1}\right)$, myo-inositol $\left(0.1 \mathrm{gl}^{-1}\right)$, maltose $\left(50 \mathrm{gl}^{-1}\right)$, polyethylene glycol 4000 (PEG) $\left(100 \mathrm{~g} \mathrm{l}^{-1}\right)$, activated charcoal $\left(2 \mathrm{~g} \mathrm{l}^{-1}\right)$ and gelled with Phytagel ${ }^{\circledR}\left(3 \mathrm{gl}^{-1}\right)$. The cultures were incubated for 30 days with $16 \mathrm{~h}$ photoperiod, with a low light intensity of $5-10 \mu \mathrm{mol} \mathrm{m}^{-2} \mathrm{~s}^{-1}$ provided by cool-White OSRAM $^{\mathrm{TM}}$ fluorescent lamps, at $22 \pm 2{ }^{\circ} \mathrm{C}$, and then transferred to the maturation phase II (MPII) culture medium.

MPII culture medium consisted of the same MPI culture medium composition plus different ABA concentrations (0, 25 and $75 \mu \mathrm{M})$. The ABA stock solution was filter sterilized and added to the culture medium after autoclaving. The cultures were incubated for 30 days with $16 \mathrm{~h}$ photoperiod, with a low light intensity of $5-10 \mu \mathrm{mol} \mathrm{m}^{-2} \mathrm{~s}^{-1}$, at $22 \pm 2{ }^{\circ} \mathrm{C}$. The number of somatic embryos obtained was counted manually with the help of a stereo microscope at $3 \mathrm{x}$ magnification after 15 and 30 days inoculation in MPII culture medium. Cultures monitoring was carried out in Olympus SZH10 Zoom stereo microscope equipped with a computercontrolled digital camera (DP71, Olympus Center Valley, PA, USA).

The experimental design was completely randomized with five replications, and the experimental unit consisted of a Petri dish containing EC. Data were submitted to analysis of variance (ANOVA), followed by Student-Newman-Keuls (SNK) mean separation test $(p<0.05)$, using Statistica ${ }^{\circledR} 6.0$ for Windows version 8.0.

\subsection{Light microscopy analysis}

Light microscopy technique was used to monitor the development sequence of individually selected somatic embryos derived from the best ABA-supplemented maturation treatment after 0, 15 and 30 days culture on MPII.

Representative samples of $P$. lambertii somatic embryos in different developmental stages were collected and fixed in paraformaldehyde (2.5\%) in sodium phosphate buffer $0.2 \mathrm{M}(\mathrm{pH}$ 7.2 ) for $24 \mathrm{~h}$ at $4{ }^{\circ} \mathrm{C}$. The samples were then washed three times in 
buffer without fixative and gradually dehydrated in graded ethanol series (30-100\%). The samples were embedded in methacrylate resin (Leica Historesin ${ }^{\circledR}$ ) according to manufacturer's instructions. Sections of 5-7 $\mu \mathrm{m}$, obtained using a rotary microtome (Slee Technik $\left.^{\circledR}\right)$, were allowed to adhere to histological slides at $42 \pm 2{ }^{\circ} \mathrm{C}$, using few drops of water. After water evaporation, sections were stained with $1 \%$ toluidine blue in an aqueous solution of $1 \%$ Borax, pH 9 [24], and relevant aspects have been identified and photographed using an inverted microscope (Olympus IX81), equipped with a computer-controlled digital camera.

\subsection{Glutathione supplementation experiments during MPI}

In order to evaluate the effect of different GSH levels supplemented to MPI culture medium, EC maintained in proliferation cycles in cell suspension were used. The same procedures described above were performed, and EC was cultured on $90-\mathrm{mm}$ diameter Petri dishes containing $25 \mathrm{ml}$ of MPI culture medium, and the Petri dishes sealed with PVC-film. This culture medium consisted of the same MPI medium composition described above plus different GSH concentrations $(0,0.1$ and $0.5 \mathrm{mM})$. Cultures were incubated for 30 days with $16 \mathrm{~h}$ photoperiod, with a low light intensity of 5-10 $\mu \mathrm{mol} \mathrm{m}^{-2} \mathrm{~s}^{-1}$, at $22 \pm 2{ }^{\circ} \mathrm{C}$, and then transferred to the MPII culture medium.

MPII culture medium consisted of the same MPI culture medium composition without GSH and plus the best ABA concentration obtained in the previous experiment. Cultures were incubated for 20 days with $16 \mathrm{~h}$ photoperiod, with a low light intensity of $5-10 \mu \mathrm{mol} \mathrm{m}^{-2} \mathrm{~s}^{-1}$, at $22 \pm 2{ }^{\circ} \mathrm{C}$. The number of somatic embryos obtained was evaluated after 0,10 and 20 days inoculation in MPII culture medium. Cultures monitoring was carried out in stereo microscope equipped with a computer-controlled digital camera.

The experimental design was completely randomized with five replications, and the experimental unit consisted of a Petri dish containing EC. Data were submitted to ANOVA, followed by SNK mean separation test $(\mathrm{p}<0.05)$, using Statistica ${ }^{\circledR} 6.0$ for Windows version 8.0

Samples of EC containing somatic embryos obtained from different MPI treatments after 0, 10 and 20 days inoculation in MPII culture medium were collected for ABA, $\mathrm{Z}$ and SA quantification.

\section{5. $A B A, z$ and $S A$ quantification}

The sample extraction and analysis were performed according to an adapted protocol from Müller and Munné-Bosch [25] and Dobrev and Vankova [26]. Lyophilized samples were weighed ( $\sim 20 \mathrm{mg}$ DW) in $2 \mathrm{ml}$ microtubes and ground with $800 \mu$ l of extraction solvent (methanol:water:formic acid 75:20:5, v/v). Then, the microtubes were kept in $-20^{\circ} \mathrm{C}$ overnight and then extracted for $25 \mathrm{~min}$ at $4{ }^{\circ} \mathrm{C}$ in an ultrasonic bath ( $40 \mathrm{kHz}$ frequency), followed by centrifugation at $1,500 \mathrm{xg}$ for $10 \mathrm{~min}$ at $4{ }^{\circ} \mathrm{C}$. The pellet was re-extracted 3 more times with $400 \mu$ l of extraction solvent and sonicated at the same condition. After the last centrifugation, supernatants were combined, dried in a vacuum concentrator, resuspended in $75 \mu \mathrm{l}$ of methanol and filtered through a $0.22 \mu \mathrm{m}$ PTFE filter. Samples were then analyzed by LC-MS/MS.

The system consisted of an Acquity UPLC ${ }^{\mathrm{TM}}$ System (Waters, USA) quaternary pump equipped with an autosampler. An Acquity UPLC BEH C18 (Waters, USA) column $(2.1 \times 50 \mathrm{~mm}, 1.7 \mu \mathrm{m})$ was used. The mobile phase in the chromatographic separation consisted of a binary mixture of eluent $\mathrm{A}(0.05 \%$ glacial acetic acid in water) and eluent $B$ ( $0.05 \%$ glacial acetic acid in acetonitrile). The gradient consisted of $1 \%$ to $100 \% \mathrm{~B}$ in $2.2 \mathrm{~min}$, and kept at $100 \% \mathrm{~B}$ up to $2.8 \mathrm{~min}$ at the flow rate of $0.3 \mathrm{ml} \mathrm{min}^{-1}$, with column temperature of $40^{\circ} \mathrm{C}$. An injection volume of $5 \mu \mathrm{l}$ was applied in all analyses. The tandem MS analyses were carried out on a Waters Xevo ${ }^{\mathrm{TM}}$

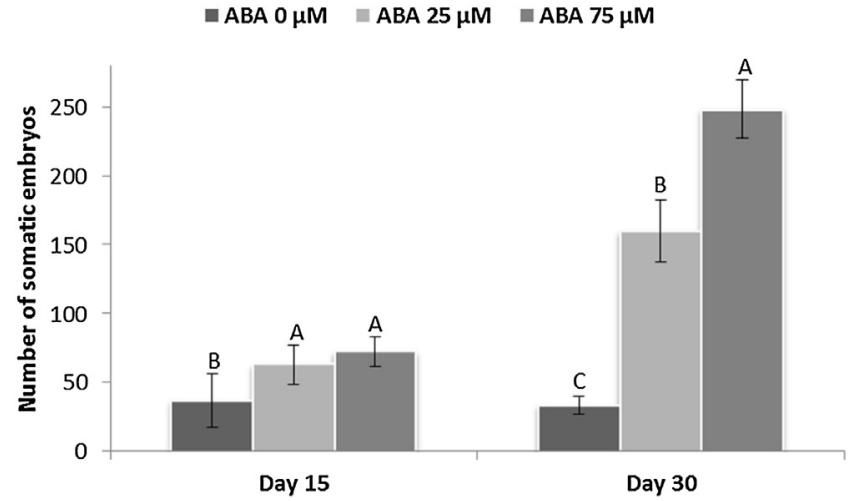

Fig. 1. Somatic embryos number after 15 and 30 days in maturation phase II culture medium with different ABA concentrations $(0,25$ and $75 \mu \mathrm{M})$. Mean values \pm standard deviation. Different letters between treatments indicate significant differences at the same evaluation time according to the SNK test $(\mathrm{p}<0.05)$.

triple quadrupole mass spectrometer system (MS/MS) equipped with an ESI interface and adjusted with the following conditions: capillary voltage, $2.5 \mathrm{kV}$; source temperature, $150^{\circ} \mathrm{C}$, desolvation temperature, $400{ }^{\circ} \mathrm{C}$; desolvation gas flow, $800 \mathrm{~h} \mathrm{~h}^{-1}$; cone gas flow, $201 \mathrm{~h}^{-1}$. Multiple reaction monitoring (MRM) mode was used and the parameters of MS/MS detection were optimized to each hormone. Analysis of $\mathrm{Z}$ was performed in positive ionization ( $\mathrm{ESI}^{+}$, $220>136 \mathrm{~m} / z$, cone $30 \mathrm{~V}$, collision $17 \mathrm{~V})$, while $\mathrm{ABA}(263>153 \mathrm{~m} / \mathrm{z}$, cone $40 \mathrm{~V}$, collision $20 \mathrm{~V})$ and $\mathrm{SA}(137>93 \mathrm{~m} / \mathrm{z}$, cone $34 \mathrm{~V}$, collision $18 \mathrm{~V}$ ) were performed in negative ionization $\left(\mathrm{ESI}^{-}\right)$.

Accurately weighed solid portions of ABA (A1049), SA (S5922) and Z (Z0164) standards (Sigma-Aldrich) were dissolved in methanol to prepare $1 \mathrm{mg} \mathrm{ml}^{-1}$ of stock solutions. All stock solutions were stored under darkness at $-20^{\circ} \mathrm{C}$. Working solutions were prepared from stock solutions with serially dilution in methanol immediately before use. The standard curve, with the concentration sequence of $5,10,50,100,200,400,800,1600$ and $3200 \mathrm{ng} \mathrm{ml}^{-1}$, was prepared in three independents dilutions in the black matrix (methanol) with analysis/quantification in LC-MS/MS in triplicate. TargetLynx ${ }^{\mathrm{TM}}$ software (Waters, USA) was used for quantification, with limit of detection (LOD) greater than 3 , and the limit of quantification (LOQ) greater than 10 . To determine the recovery efficiency and matrix effect, as described by Trufelli et al. [27], $100 \mathrm{ng} \mathrm{ml}^{-1}$ of standards were spiked in each sample at the beginning of extraction. In parallel, samples were extracted without spiking. The recovery and the matrix effect were determined by comparing the peak areas of the analytical standard spiked before and after extraction.

Data obtained was subjected to one-way analysis of variance (ANOVA) to test the significance of variations in $A B A$, $\mathrm{SA}$ and $\mathrm{Z}$ endogenous level of EC containing somatic embryos during maturation. For Post Hoc mean result comparisons, Student-Newman-Keuls (SNK) method $(\mathrm{p}<0.05)$ was performed by Statistica ${ }^{\circledR} 6.0$ for Windows version 8.0.

\section{Results and discussion}

\subsection{ABA supplementation enhances somatic embryos formation and development}

Significant differences were found in somatic embryos number obtained during MPII treatments, with different levels of ABA supplementation (Fig. 1). At day 15 of maturation, 37 somatic embryos/Petri dish were observed in ABA-free treatment. In the same evaluation time, improved somatic embryos formation was observed in ABA-supplemented treatments. At day 30 of MPII, 


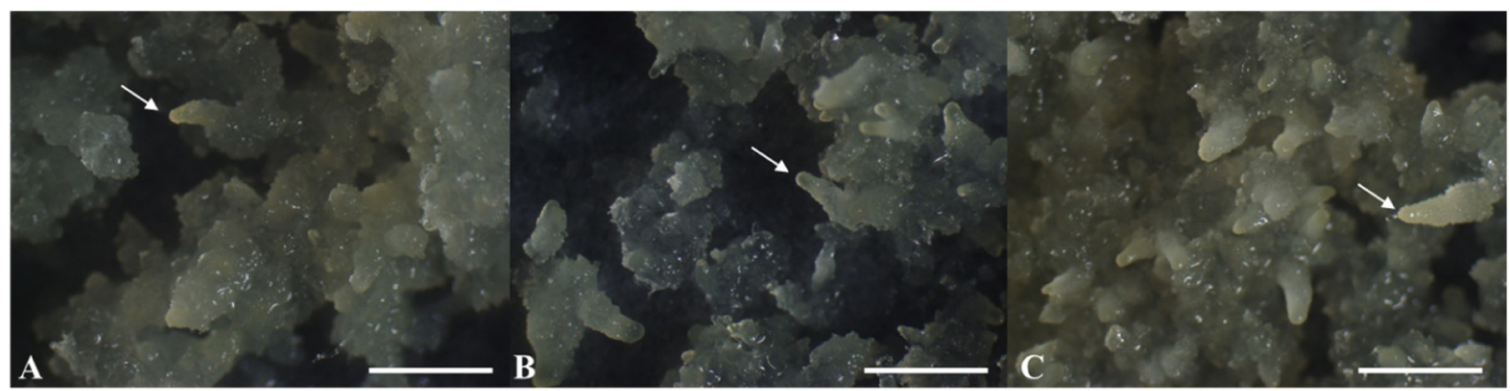

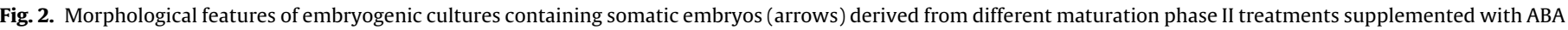
$0 \mu \mathrm{M}(\mathrm{A}), \mathrm{ABA} 25 \mu \mathrm{M}$ (B) and ABA $75 \mu \mathrm{M}$ (C) after 30 days in culture. Bar: $2.0 \mathrm{~mm}$.

the best treatment was ABA $75 \mu \mathrm{M}$, followed by ABA $25 \mu \mathrm{M}$ and ABA $0 \mu \mathrm{M}$. The improved number of somatic embryos formed in ABA-supplemented treatments highlights the relevance of $A B A$ supplementation during somatic embryos maturation process of P. lambertii.

Morphological analysis also demonstrated more organized and developed somatic embryos formation in ABA-supplemented maturation treatments (Fig. 2). After 30 days MPII, somatic embryos in early torpedo developmental stage were found, especially in ABA-supplemented maturation treatments (Fig. 2B,C).

ABA plays a key role in many plant developmental processes, including the promotion of seed desiccation tolerance, maturation of embryos and seed development [28]. ABA also acts as a controlling factor of germination and dormancy in somatic embryos, and is generally used to induce somatic embryos into a quiescent state during plant tissue culture [28]. Furthermore, ABA not only promotes the transition of somatic embryos from the proliferation to the maturation phase, but it has also been used to enhance embryo morphological features by increasing desiccation tolerance and preventing precocious germination [28-30].

The yield of mature somatic embryos of Norway spruce on ABA-containing medium was increased up to 10 -fold when a pretreatment of 1-9 days with this plant growth regulator was applied [31]. Zhang et al. [32] reported the role of exogenously applied ABA during different stages of Arabidopsis thaliana embryo development, further suggesting that the promotion of somatic embryos development is ABA-dependent. In the present study, ABA supplementation also improved somatic embryos morphological features and number, in agreement with these previous reports.

Production of synchronous mature somatic embryos that undergo a period of arrest during development is a prerequisite for a successful somatic embryogenesis protocol [14]. Larch somatic embryos cultured on ABA-supplemented culture medium were synchronous and developed coherently into late cotyledonary embryos, while somatic embryos obtained on ABA-free culture medium were asynchronous and with different morphological features [33]. Here, we did not quantitatively evaluate embryos synchrony, but we observed the presence of somatic embryos in higher developmental stages in ABA-supplemented treatments.

Thus, ABA supplementation in the culture medium during MPII appears to substantially increase the number and morphological features of $P$. lambertii somatic embryos, and should be performed in order to promote their further development.

\subsection{Light microscopy analysis of somatic embryos}

Globular somatic embryos at the onset of polarization showing a well-delimited protoderm were the first clearly distinguishable stage of somatic embryo histodifferentiation (Fig. 3A). A layer of embryonal tube cells and suspensor-like cells was also evident, which appeared to be more vacuolated as compared to cells of the embryonic head. Subsequent somatic embryo development included their elongation, development of procambium and shoot meristem differentiation, reaching the early torpedo-staged somatic embryo (Fig. 3B). Finally, an increased embryo elongation was observed, which became sharper, reaching the late torpedostaged somatic embryo (Fig. 3C). Morphological features of the respective somatic embryo stages used in the histological analysis are indicated in Fig. 3D (arrows).

Very similar histological features were also observed during somatic embryo development in other Brazilian non-pinaceae conifer, Araucaria angustifolia [7]. These authors reported a conspicuous presence of intercellular spaces, especially in torpedo-staged somatic embryo, unlike the results found in the present study. The absence of these intercellular spaces in P. lambertii somatic embryos may indicate a better embryonic development. Poorly developed shoot apical meristems, disrupted by the presence of large intercellular air spaces, have been reported in many genera of conifers, as reviewed by Stasolla and Yeung [29].

Somatic embryos in the first stages of development of A. angustifolia were characterized by individualized structures composed of two polarized regions: a dense globular embryonic head connected to a suspensor region [34]. The embryonic head was composed by embryogenic cells, and the suspensor region was composed by suspensor cells [34]. These authors also described a transitional region between these both regions. Our results also indicated these features, especially in the globular-staged somatic embryo.

In our study, during the transition of early torpedo- to late torpedo-staged somatic embryos, we observed an enlargement of embryonic head and an improved organization of suspensor structure (Fig. 3C). Similarly, Morel et al. [15] reported that meristematic centers gradually enlarged, and suspensor cells became well organized, comprising a number of long narrow cells after 3 weeks maturation of Pinus pinaster EC. Histological features found in the present study are also in agreement to histological analysis performed in distinct developmental stages of Picea abies somatic embryos, a Pinaceae conifer, which showed similar pattern of ultrastructural organization [35]. However, the subsequent stages of torpedo-staged somatic embryos were not achieved with the maturation treatment tested in the present study.

\subsection{Different supplemented glutathione levels improve somatic embryos maturation}

The effect of different glutathione levels supplemented to maturation culture MPI on $P$. lambertii somatic embryos maturation was investigated, and pronounced differences in embryo number and morphological features were observed. At inoculation time in MPII culture medium (after 30 days on MPI), treatment with GSH $0.5 \mathrm{mM}$ indicated the highest number of somatic embryos/Petri dish, followed by GSH $0.1 \mathrm{mM}$ and GSH $0 \mathrm{mM}$ (Fig. 4). The same scenario was observed in day 10 MPII, with 659, 467 and 299.2 somatic 
A

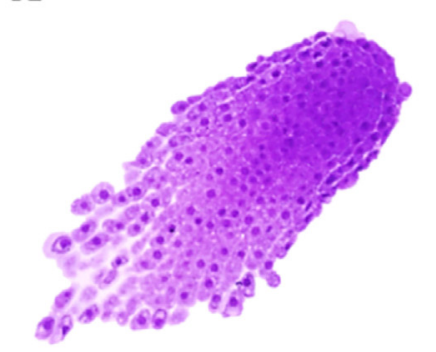

B

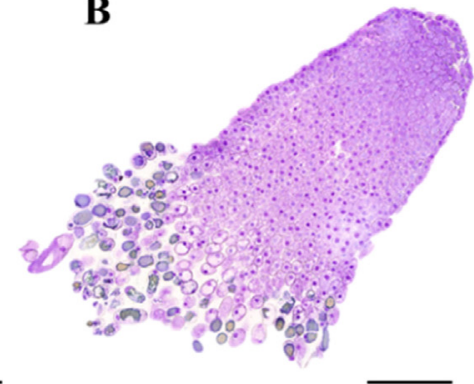

C

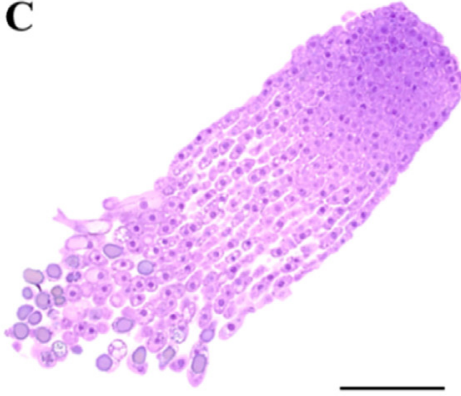

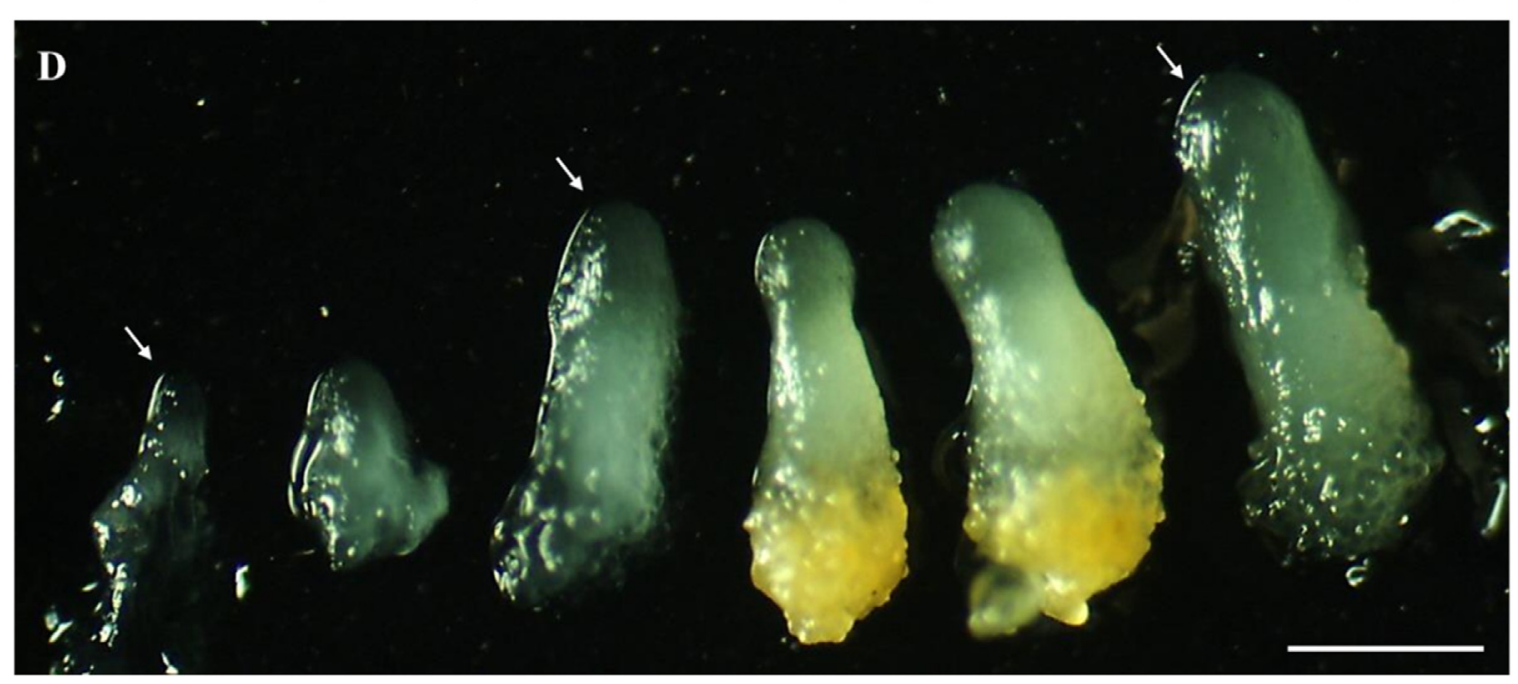

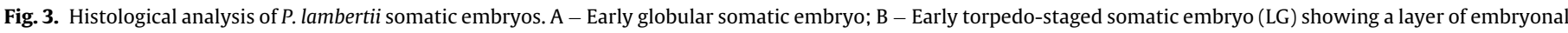

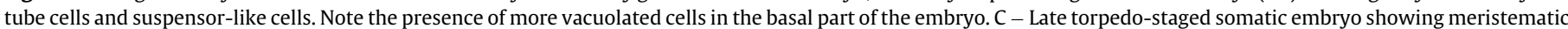

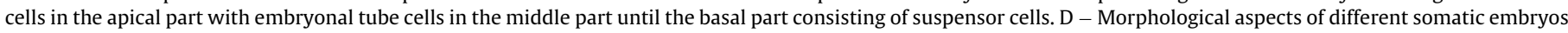
developmental stages. Arrows indicate the early globular, early torpedo and late torpedo-staged somatic embryos. Bar figures A, B and C: $200 \mu \mathrm{m}$. Bar figure D: $1.0 \mathrm{~mm}$.

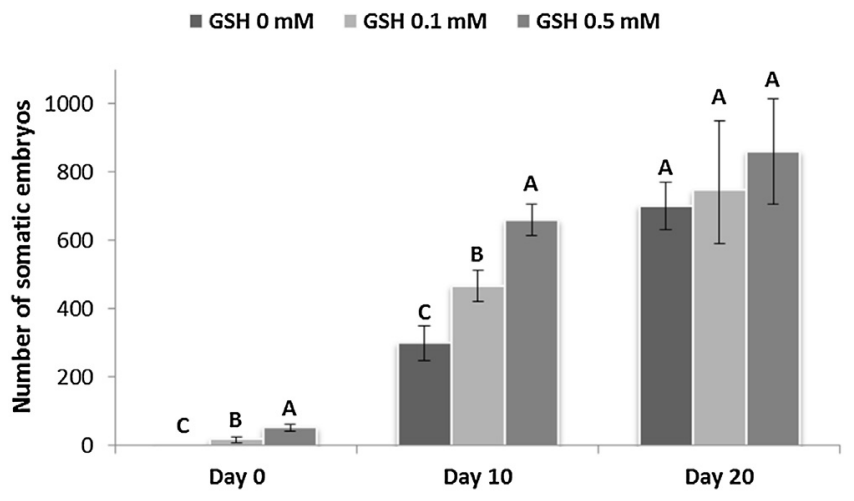

Fig. 4. Somatic embryos number after 0,10 and 20 days in maturation phase II culture medium derived from treatments supplemented with different GSH concentrations $(0,0.1$ and $0.5 \mathrm{mM})$ during the maturation phase $I$. Mean values \pm standard deviation. Different letters between treatments indicate significant differences at the same evaluation time according to the SNK test $(\mathrm{p}<0.05$ ).

embryos/Petri dish in GSH 0.5, GSH 0.1 and GSH 0 mM treatments, respectively. However, no statistical difference was found between treatments in day 20 MPII. Nevertheless, it is important to emphasize that GSH-supplemented treatments indicated more developed somatic embryos as compared to GSH-free treatment in this evaluation time (Fig. 5).

Glutathione is an important antioxidant that protects cells against oxidative stress and functions in biosynthetic pathways, antioxidant biochemistry and redox homeostasis [36]. Changes in the glutathione redox state play an important role in a number of biological processes where they affect many cell activities and func- tions, including somatic embryo yield and morphological features [16]. Pullman et al. [17] found that culture medium supplementation with GSH increased early-stage somatic embryo growth and embryogenic tissue culture initiation for cultures of Pinus taeda and Pinus menziesii.

Belmonte and Yeung [37] also reported an increased total number of somatic embryos in Picea glauca in response to the supplementation of $0.1 \mathrm{mM} \mathrm{GSH}$ in the ABA-containing maturation culture medium. These authors also observed a significantly higher number of somatic embryos that were able to develop to the mature cotyledonary stage. Our study indicated similar results, with an improvement in mature somatic embryos formation in GSH-supplemented treatments (Fig. 5).

Glutathione supplementation at low levels (0.01 and $0.1 \mathrm{mM}$ ) increased the number of $A$. angustifolia early somatic embryos, with $35 \%$ of total pro-embryogenic mass indicating polarization after 7 days culture, in contrast to GSH-free treatment (8\%). However, EC maintenance for longer than 7 days in an environment with high redox potential proved to be deleterious to the early somatic embryos development, causing the somatic embryos oxidation and death [21].

A reduced glutathione environment during the induction of the embryogenic process increases the number of immature somatic embryos, whereas the imposition of an oxidized environment ensures the proper completion of the developmental program [16]. In the present study, the somatic embryos obtained in GSH-supplemented treatments reached advanced developmental stages. Thus, the manipulation of GSH/GSSG (glutathione disulfide) ratio, transferring the EC to a culture medium supplemented with GSSG during the final maturation process, may be a suitable strategy to develop a more efficient embryogenic system for $P$. lambertii. 


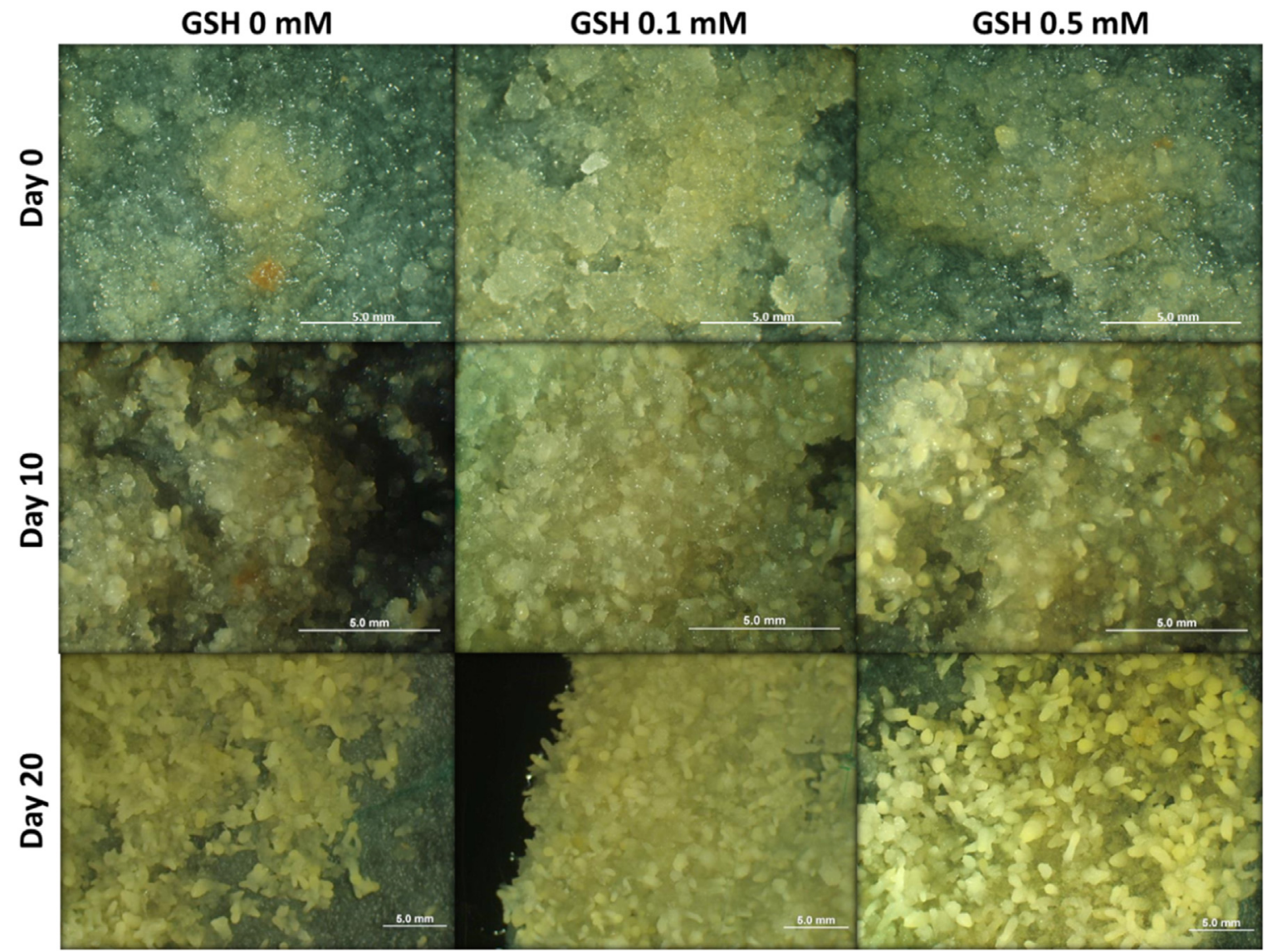

Fig. 5. Morphological features of embryogenic cultures containing somatic embryos derived from different maturation phase I treatments supplemented with GSH 0 , 0.1 and $0.5 \mathrm{mM}$ after 0,10 and 20 days in maturation phase II. Bar: $5 \mathrm{~mm}$.

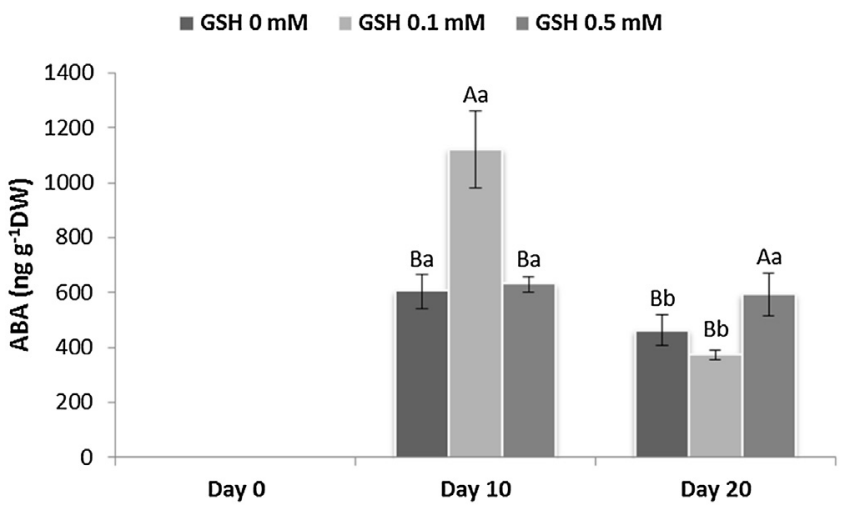

Fig. 6. Abscisic acid (ABA) endogenous levels of embryogenic cultures after 0 , 10 and 20 days in maturation phase II culture medium derived from treatments supplemented with different GSH concentrations $(0,0.1$ and $0.5 \mathrm{mM})$ during the maturation phase I. Mean values \pm standard deviation. Different uppercase letters indicate significant differences at the same evaluation time, and different lowercase letters indicate significant differences along the evaluation times within treatments, according to the SNK test $(\mathrm{p}<0.05)$. DW: dry weight.

\subsection{GSH supplementation affects endogenous levels of $A B A, z$ and} SA during embryos maturation

Endogenous levels of ABA, Z and SA from EC submitted to different GSH-supplemented maturation treatments indicated diverse accumulation dynamics (Figs. 6-8). Despite the observed matrix effect in hormone quantification, this influence was constant in all treatments and did not interfere in the results. It was verified an

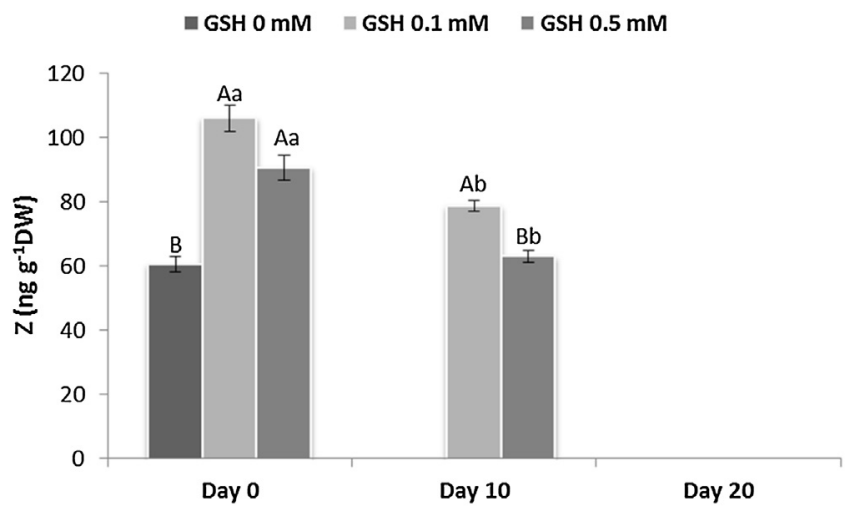

Fig. 7. Zeatin ( $Z$ ) endogenous levels of embryogenic cultures after 0,10 and 20 days in maturation phase II culture medium derived from treatments supplemented with different GSH concentrations $(0,0.1$ and $0.5 \mathrm{mM})$ during the maturation phase $\mathrm{I}$. Mean values \pm standard deviation. Different uppercase letters indicate significant differences at the same evaluation time, and different lowercase letters indicate significant differences along the evaluation times within treatments, according to the SNK test $(\mathrm{p}<0.05)$. DW: dry weight.

increase of 11.55 fold in $\mathrm{ABA}$ and a decrease of 0.66 fold for $\mathrm{Z}$ and 0.38 fold for SA.

At day 0 MPII, no detectable ABA was observed in any treatment (Fig. 6). After 10 days of MPII, GSH $0.1 \mathrm{mM}$ treatment indicated the highest ABA levels $\left(1,120.7 \mathrm{ng} \mathrm{g}^{-1} \mathrm{DW}\right)$, followed by GSH $0.5 \mathrm{mM}$ $\left(630 \mathrm{ng} \mathrm{g}^{-1} \mathrm{DW}\right)$ and GSH $0 \mathrm{mM}\left(604.2 \mathrm{ngg}^{-1} \mathrm{DW}\right)$ treatments, which indicated equal levels. In day $20, \mathrm{GSH} 0.1 \mathrm{mM}$ and GSH $0 \mathrm{mM}$ treatments indicated the lowest ABA levels (373.3 and $461.5 \mathrm{ng} \mathrm{g}^{-1}$ DW, respectively), and GSH $0.5 \mathrm{mM}$ the highest (593.1 $\mathrm{ng} \mathrm{g}^{-1} \mathrm{DW}$ ). 


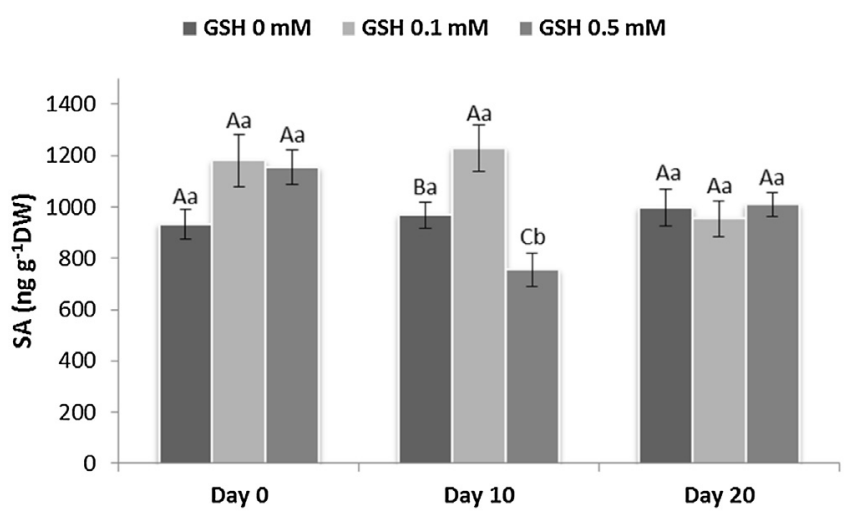

Fig. 8. Salicylic acid (SA) endogenous levels of embryogenic cultures after 0,10 and 20 days in maturation phase II culture medium derived from treatments supplemented with different GSH concentrations $(0,0.1$ and $0.5 \mathrm{mM})$ during the maturation phase I. Mean values \pm standard deviation. Different uppercase letters indicate significant differences at the same evaluation time, and different lowercase letters indicate significant differences along the evaluation times within treatments, according to the SNK test ( $\mathrm{p}<0.05)$. DW: dry weight.

Contrasting the evaluation times (days 10 and 20), treatments supplemented with GSH $0 \mathrm{mM}$ and GSH $0.1 \mathrm{mM}$ indicated a decrease during maturation, while GSH 0.5 treatment showed constant ABA levels (Fig. 6).

Typically, ABA endogenous level is low during the initial phases of somatic embryo development, increases during the embryonic growth, and then decreases during the last maturation stages, at the onset of the desiccation period [29]. Several studies have reported this pattern of ABA accumulation during somatic embryos maturation on Pinus pinaster [15], carrot [38], Medicago falcata [39], Camellia sinensis [40], and Quercus suber [41,42]. In the present study, this typical behavior was specially observed on GSH $0.1 \mathrm{mM}$ treatment, which presented a much more expressive decrease in ABA endogenous levels after day 20 in maturation, as compared to the other treatments.

Few reports can be found on the literature addressing the glutathione supplementation and ABA endogenous level during somatic embryos maturation. Belmonte et al. [20] reported an improved ABA endogenous level in Brassica napus somatic embryos treated with buthionine sulfoximine (BSO), an inhibitor of glutathione de novo synthesis. These authors hypothesized that the higher availability and turnover of ABA in BSO-treated embryos may be responsible for the proper execution of all developmental events, resulting in the production of embryos with improved morphological features. Our results also indicate that glutathione supplementation affects ABA levels during embryo maturation; however, further experiments with BSO at the final maturation phase may be better elucidates this relationship.

Regarding $\mathrm{Z}$ endogenous levels, at day 0 MPII, GSHsupplemented treatments showed the highest levels as compared to GSH-free treatment (Fig. 7). After 10 days of MPII, GSH $0.1 \mathrm{mM}$ treatment resulted in the highest $Z$ levels $\left(78.64 \mathrm{ngg}^{-1} \mathrm{DW}\right)$, followed by GSH $0.5 \mathrm{mM}$ (62.9 $\left.\mathrm{ng} \mathrm{g}^{-1} \mathrm{DW}\right)$. No $\mathrm{Z}$ was detected in any treatment. In day 20 , no $\mathrm{Z}$ was detected in any treatment.

There is support for the concept that cytokinins, in general, are important during the initial cell division phase of SE, but not for later stages of embryo development and maturation $[43,44]$. This suggests that cytokinins may have a major role in cell division, but not in embryo differentiation [30].

Among the few reports regarding $\mathrm{Z}$ endogenous levels during somatic embryo maturation, Vágner et al. [45] found that cytokinin levels, including $Z$, dramatically dropped after ABA supplementation to culture medium during Picea abies somatic embryo maturation, and this decrease were correlated to ABA concentra- tion used. In contrast, hybrid larch somatic embryos showed an increased cytokinin level during the maturation period [46]. A similar pattern was also found in larch somatic embryos submitted to maturation in presence activated charcoal, with this increase being dependent on whether the medium was supplemented with charcoal [47].

A correlation between decreased $Z$ levels and embryogenic potential has also been reported. Pérez-Jiménez et al. [10] found a higher $Z$ endogenous content in Prunus persica non-embryogenic cultures than in embryogenic ones. Similar results were reported in embryogenic genotypes of hazelnut, where $Z$ levels were found [48], as well as in coconut embryogenic cultures [49]. The results of the present work corroborate these findings, where undetectable $Z$ levels were found in more advanced stages of somatic embryos maturation.

Levels of SA were also evaluated, as shown in Fig. 8. At day zero MPII, no differences were observed between treatments. Differently, in day 10 of maturation, GSH $0.1 \mathrm{mM}$ treatment indicated highest levels of SA $\left(1,227.2 \mathrm{ng} \mathrm{g}^{-1} \mathrm{DW}\right)$, followed by GSH $0 \mathrm{mM}$ (969 $\mathrm{ng} \mathrm{g}^{-1} \mathrm{DW}$ ) and GSH $0.5 \mathrm{mM}$ (754.7 $\mathrm{ng} \mathrm{g}^{-1} \mathrm{DW}$ ). Again, no differences were observed at day 20 of maturation. Contrasting the SA levels along the evaluation times, only GSH $0.5 \mathrm{mM}$ treatment indicated significant differences, with a substantial decrease at day 10 of maturation, followed by an increase.

Salicylic acid belongs to the large group of plant phenolics, being ubiquitous in higher plants, and an important signaling molecule involved in plant defense responses to pathogens and abiotic stress, as well as in plant growth and development [50,51]. During SE of Astragalus adsurgens, SA supplementation to maturation culture medium significantly enhanced somatic embryos formation [52]. In the same way, picomolar SA concentrations exogenously applied in Coffea arabica embryogenic cultures induced cellular growth, and enhanced the number and morphological features of somatic embryos [53]. A plausible explanation may be that SA has a biphasic effect in plants: when SA is at a low concentration it can induce cellular reprogramming of somatic cells into the embryogenic stage, while at a high concentration this reprogramming can be inhibited, inducing another cellular reprogram for cellular viability to be preserved [54].

Results observed in GSH $0.5 \mathrm{mM}$ treatment, in our study, indicated the lowest SA levels at day 10 maturation, period coincident with early embryonic development. This treatment, in the same evaluation time, indicated the highest somatic embryos formation as compared to the other treatments. In this sense, a correlation between lower SA levels and improved somatic embryo formation can be hypothesized, corroborating to these findings.

Kanno et al. [55], investigating the pattern of SA endogenous accumulation during Arabidopsis thaliana zygotic embryos development, reported that the SA levels were relatively high at early embryonic stages, decreasing in mid-development and subsequently increasing in late stages. Again, GSH $0.5 \mathrm{mM}$ treatment showed this same accumulation pattern, reinforcing the idea of GSH supplementation at this concentration may be improve the redox status during $P$. lambertii somatic embryo development.

\section{Conclusion}

Taken together, the results of present study provided consistent data to improve the SE morphogenetic route in non-Pinaceae conifers, as is the case of $P$. lambertii. The central role of ABA in the somatic embryos maturation process of $P$. lambertii was demonstrated, being apparently essential as a maturation promoter. In addition, glutathione supplementation on the MPI culture medium resulted in pronounced differences in embryo number and morphological features. Somatic embryos obtained in 
GSH-supplemented treatments reached advanced developmental stages; however, the final stages of maturation and conversion could not be achieved. Thus, the manipulation of GSH/GSSG ratio during the final maturation process may be a suitable strategy to develop a more efficient embryogenic system in $P$. lambertii.

Finally, endogenous levels of ABA, Z and SA from EC submitted to different GSH-supplemented maturation treatments indicated diverse accumulation dynamics. Our results indicated that GSH supplementation affects ABA levels during embryo maturation; however, further experiments with BSO at the final maturation phase may better elucidate this relationship. Regarding to $\mathrm{Z}$ endogenous levels, all treatments indicated significant decreased levels during the maturation phase, supporting the concept that cytokinins, in general, are important during the initial cell division phase of somatic embryogenesis, but not for the later stages of embryo development and maturation. In addition, a correlation between lower SA levels and improved somatic embryo formation were hypothesized.

\section{Authors contribution}

Conceived and designed the experiments: HPFF, LNV and MPG; Performed the in vitro culture experiments: HPFF, LNV and CCP; Performed the LC-MS/MS quantification and data analysis: HPFF, LNV, JAG and HPS; Contributed reagents/materials/analysis tools: HPS and MPG; Wrote the paper: HPFF, LNV and MPG.

\section{Acknowledgements}

This work was supported by Coordenação de Aperfeiçoamento de Pessoal de Nível Superior (CAPES), Conselho Nacional de Desenvolvimento Científico e Tecnológico (CNPq 306126/2013-3), and Fundação de Amparo à Pesquisa e Inovação do Estado de Santa Catarina (FAPESC 14848/2011-2, 3770/2012, and 2780/2012-4). The authors thank to Dr. Adelar Mantovani and José Antônio Ribas Ribeiro for kindly provide Podocarpus lambertii seeds for somatic embryogenesis induction. The authors are also grateful to Dr. Emanuel Maltempi de Souza, Dr. Lauro Souza and Dr. Marcelo Muller-Santos for the important insights about the hormones quantification.

\section{References}

[1] M. Ahuja, D. Neale, Evolution of genome size in conifers, Silvae Genet. 54 (2005) 126-137

[2] T.T. Veblen, J.J. Armesto, B.R. Burns, T. Kitzberger, A. Lara, R. Young, The coniferous forests of south america, in: Ecosyst, World Conifer. For., Amsterdam, 2005, pp. 701-725.

[3] A. Farjon, D. Filer, An Atlas of the World's Conifers: an Analysis of Their Distribution, Biogeography, Diversity and Conservation Status, Brill, Leiden-Boston, 2013.

[4] N. Myers, R.A. Mittermeier, C.G. Mittermeier, G.A.B. da Fonseca, J. Kent, Biodiversity hotspots for conservation priorities, Nature 403 (2000) 853-858, http://dx.doi.org/10.1038/35002501.

[5] M.P. Guerra, V. Silveira, A.L.W. Dos Santos, L.V. Astarita, R.O. Nodari, Somatic embryogenesis in Araucaria angustifolia (Bert) O. Kuntze, in: Somat. Embryog. Woody Plants (2000) pp. 457-578. 10.1007/978-94-017-3030-3_15.

[6] K. Klimaszewska, C. Overton, D. Stewart, R.G. Rutledge, Initiation of somatic embryos and regeneration of plants from primordial shoots of 10 -year-old somatic white spruce and expression profiles of 11 genes followed during the tissue culture process, Planta 233 (2011) 635-647, http://dx.doi.org/10.1007/ s00425-010-1325-4.

[7] H.P.F. Fraga, L.N. Vieira, C.C. Puttkammer, E.M. Oliveira, M.P. Guerra, Time-lapse cell tracking reveals morphohistological features in somatic embryogenesis of Araucaria angustifolia (Bert) O. Kuntze, Trees - Struct. Funct. 29 (2015) 1613-1623, http://dx.doi.org/10.1007/s00468-015-1244-X.

[8] O. Karami, A. Saidi, The molecular basis for stress-induced acquisition of somatic embryogenesis, Mol. Biol. Rep. 37 (2010) 2493-2507, http://dx.doi. org/10.1007/s11033-009-9764-3.

[9] C.X. Zhang, Q. Li, L. Kong, Induction, development and maturation of somatic embryos in Bunge's pine (Pinus bungeana Zucc. ex Endl.), Plant Cell Tissue
Organ Cult. 91 (2007) 273-280, http://dx.doi.org/10.1007/s11240-007-92944.

[10] M. Pérez-Jiménez, E. Cantero-Navarro, F. Pérez-Alfocea, I. Le-Disquet, A. Guivarc'h, J. Cos-Terrer, Relationship between endogenous hormonal content and somatic organogenesis in callus of peach (Prunus persica L. Batsch) cultivars and Prunus persica $\times$ Prunus dulcis rootstocks, J. Plant Physiol. 171 (2014) 619-624, http://dx.doi.org/10.1016/j.jplph.2014.01.006.

[11] I. Ruduś, E. Kępczyńska, J. Kępczyński, Comparative efficacy of abscisic acid and methyl jasmonate for indirect somatic embryogenesis in Medicago sativa L, Plant Growth Regul. 48 (2006) 1-11, http://dx.doi.org/10.1007/s10725005-5136-8.

[12] I. Ruduś, E.W. Weiler, E. Kepczyńska, Do stress-related phytohormones, abscisic acid and jasmonic acid play a role in the regulation of Medicago sativa L. somatic embryogenesis? Plant Growth Regul. 59 (2009) 159-169, http://dx. doi.org/10.1007/s10725-009-9399-3.

[13] S. Von Arnold, I. Sabala, P. Bozhkov, J. Dyachok, L. Filonova, Developmental pathways of somatic embryogenesis, Plant Cell. Tissue Organ Cult. 69 (2002) 233-249, http://dx.doi.org/10.1023/A:1015673200621.

[14] M.A. Lelu-Walter, D. Thompson, L. Harvengt, L. Sanchez, M. Toribio, L.E. Pâques, Somatic embryogenesis in forestry with a focus on Europe: state-of-the-art, benefits, challenges and future direction, Tree Genet Genomes 9 (2013) 883-899, http://dx.doi.org/10.1007/s11295-013-0620-1.

[15] A. Morel, C. Teyssier, J.-F. Trontin, K. Eliasova, B. Pesek, M. Beaufour, D. Morabito, N. Boizot, C. Le Metté, L. Belal-Bessai, I. Reymond, L. Harvengt, M. Cadene, F. Corbineau, M. Vágner, P. Label, M.A. Lelu-Walter, Early molecular events involved in Pinus pinaster Ait. somatic embryo development under reduced water availability: transcriptomic and proteomic analyses, Physiol. Plant. 152 (2014) 184-201, http://dx.doi.org/10.1111/ppl.12158.

[16] C. Stasolla, Glutathione redox regulation of in vitro embryogenesis, Plant Physiol. Biochem. 48 (2010) 319-327, http://dx.doi.org/10.1016/j.plaphy. 2009.10.007.

[17] G.S. Pullman, X. Zeng, B. Copeland-Kamp, J. Crockett, J. Lucrezi, S.W. May, K. Bucalo, Conifer somatic embryogenesis: improvements by supplementation of medium with oxidation-reduction agents, Tree Physiol. 35 (2015) 209-224, http://dx.doi.org/10.1093/treephys/tpu117.

[18] C.H. Foyer, G. Noctor, Ascorbate and glutathione: the heart of the redox hub, Plant Physiol. 155 (2011) 2-18, http://dx.doi.org/10.1104/pp.110.167569.

[19] M.F. Belmonte, G. Donald, D.M. Reid, E.C. Yeung, C. Stasolla, Alterations of the glutathione redox state improve apical meristem structure and somatic embryo quality in white spruce (Picea glauca), J. Exp. Bot. 56 (2005) 2355-2364, http://dx.doi.org/10.1093/jxb/eri228.

[20] M.F. Belmonte, S.J. Ambrose, A.R.S. Ross, S.R. Abrams, C. Stasolla, Improved development of microspore-derived embryo cultures of Brassica napus cv Topaz following changes in glutathione metabolism, Physiol. Plant. 127 (2006) 690-700, http://dx.doi.org/10.1111/j.1399-3054.2006.00707.x.

[21] L. do, N. Vieira, C. Santa-Catarina, H.P. de, F. Fraga, A.L.W. dos Santos, D.A. Steinmacher, P.S. Schlogl, V. Silveira, N. Steiner, E.I.S. Floh, M.P. Guerra, Glutathione improves early somatic embryogenesis in Araucaria angustifolia (Bert) O. Kuntze by alteration in nitric oxide emission, Plant Sci. 195 (2012) 80-87.

[22] M.R. Becwar, R. Nagmani, S.R. Wann, Initiation of embryogenic cultures and somatic embryo development in loblolly pine (Pinus taeda), Can. J. For. Res. 20 (1990) 810-817, http://dx.doi.org/10.1139/x90-107.

[23] G. Pullman, P. Gupta, Method for reproducing coniferous plants by somatic embryogenesis using adsorbent materials in the development stage media, 1991. U.S. Patent No. 5036007.

[24] J. Kuo, T. O'Brien, Lignified sieve elements in the wheat leaf, Planta 117 (1974) 349-353, http://dx.doi.org/10.1007/BF00388029.

[25] M. Müller, S. Munné-Bosch, Rapid and sensitive hormonal profiling of complex plant samples by liquid chromatography coupled to electrospray ionization tandem mass spectrometry, Plant Methods. 7 (2011) 37, http://dx. doi.org/10.1186/1746-4811-7-37.

[26] P.I. Dobrev, R. Vankova, Quantification of abscisic acid, cytokinin, and auxin content in salt-stressed plant tissues, Methods Mol. Biol. 913 (2012) 251-261, http://dx.doi.org/10.1007/978-1-61779-986-0-17.

[27] H. Trufelli, P. Palma, G. Famiglini, A. Cappiello, An overview of matrix effects in liquid chromatography-mass spectrometry, Mass Spectrom. Rev. 30 (2011) 491-509, http://dx.doi.org/10.1002/mas.20298.

[28] M.K. Rai, N.S. Shekhawat, Harish, A.K. Gupta, M. Phulwaria, K. Ram, U. Jaiswal, The role of abscisic acid in plant tissue culture: a review of recent progress, Plant Cell Tissue Organ Cult. 106 (2011) 179-190, http://dx.doi.org/10.1007 s11240-011-9923-9.

[29] C. Stasolla, E.C. Yeung, Recent advances in conifer somatic embryogenesis: improving somatic embryo quality, Plant Cell. Tissue Organ Cult. 74 (2003) 15-35, http://dx.doi.org/10.1023/A:1023345803336.

[30] V.M. Jiménez, Involvement of plant hormones and plant growth regulators on in vitro somatic embryogenesis, Plant Growth Regul. 47 (2005) 91-110, http://dx.doi.org/10.1007/s10725-005-3478-x.

[31] P.V. Bozhkov, L.H. Filonova, S. Von Arnold, A key developmental switch during Norway spruce somatic embryogenesis is induced by withdrawal of growth regulators and is associated with cell death and extracellular acidification, Biotechnol. Bioeng. 77 (2002) 658-667, http://dx.doi.org/10.1002/bit.10228.

[32] H. Zhang, W. Han, I. De Smet, P. Talboys, R. Loya, A. Hassan, H. Rong, G. Jürgens, J. Paul Knox, M.H. Wang, ABA promotes quiescence of the quiescent centre and suppresses stem cell differentiation in the Arabidopsis primary 
root meristem, Plant J. 64 (2010) 764-774, http://dx.doi.org/10.1111/j.1365313X.2010.04367.x.

[33] J.H. Zhang, S.G. Zhang, S.G. Li, S.Y. Han, W.F. Li, X.M. Li, L.W. Qi, Regulation of synchronism by abscisic-acid-responsive small noncoding RNAs during somatic embryogenesis in larch (Larix leptolepis), Plant Cell. Tissue Organ Cult. 116 (2014) 361-370, http://dx.doi.org/10.1007/s11240-013-0412-1.

[34] N. Steiner, F.L. Farias-Soares, É.C. Schmidt, M.L.T. Pereira, B. Scheid, G.D. Rogge-Renner, Z.L. Bouzon, D. Schmidt, S. Maldonado, M.P. Guerra, Toward establishing a morphological and ultrastructural characterization of proembryogenic masses and early somatic embryos of Araucaria angustifolia (Bert.) O. Kuntze, Protoplasma 253 (2016) 487-501, http://dx.doi.org/10. 1007/s00709-015-0827-0.

[35] L.H. Filonova, P.V. Bozhkov, S. von Arnold, Developmental pathway of somatic embryogenesis in Picea abies as revealed by time-lapse tracking, J. Exp. Bot. 51 (2000) 249-264, http://dx.doi.org/10.1093/jexbot/51.343.249.

[36] G. Noctor, A. Mhamdi, S. Chaouch, Y. Han, J. Neukermans, B. Marquez-Garcia, G. Queval, C.H. Foyer, Glutathione in plants: an integrated overview, Plant Cell Environ. 35 (2012) 454-484, http://dx.doi.org/10.1111/j.1365-3040.2011. 02400.x.

[37] M.F. Belmonte, E.C. Yeung, The effects of reduced and oxidized glutathione on white spruce somatic embryogenesis, In Vitr. Cell Dev. Biol. Plant. 40 (2004) 61-66, http://dx.doi.org/10.1079/IVP2003483.

[38] H. Kamada, H. Harada, Changes in the endogenous level and effects of abscisic acid during somatic embryogenesis of Daucus carota L, Plant Cell Physiol. 22 (1981) 1423-1429.

[39] A. Ivanova, M. Velcheva, P. Denchev, A. Atanassov, H.A. van Onckelen, Endogenous hormone levels during direct somatic embryogenesis in Medicago falcata, Physiol. Plant. 92 (1994) 85-89, http://dx.doi.org/10.1034/j. 1399-3054.1994.920112.x.

[40] P. Sharma, S. Pandey, A. Bhattacharya, P.K. Nagar, P.S. Ahuja, ABA associated biochemical changes during somatic embryo development in Camellia sinensis (L.) O. Kuntze, J. Plant Physiol. 161 (2004) 1269-1276, http://dx.doi.org/10. 1016/j.jplph.2004.01.015.

[41] M. Pérez, M. Viejo, M. LaCuesta, P. Toorop, M.J. Cañal, Epigenetic and hormonal profile during maturation of Quercus suber L. somatic embryos, J. Plant Physiol. 173 (2015) 51-61, http://dx.doi.org/10.1016/j.jplph.2014.07.028.

[42] G. García-Martín, J.A. Manzanera, M.E. González-Benito, Effect of exogenous ABA on embryo maturation and quantification of endogenous levels of ABA and IAA in Quercus suber somatic embryos, Plant Cell Tissue Organ Cult. 80 (2005) 171-177, http://dx.doi.org/10.1007/s11240-004-1056-y.

[43] T. Fujimura, A. Komamine, Mode of action of $24-\mathrm{D}$ and zeatin on somatic embryogenesis in a carrot cell suspension culture, Zeitschrift Für Pflanzenphysiologie 99 (1980) 1-8, http://dx.doi.org/10.1016/S0044328X(80)80106-1.
[44] V.M. Jiménez, Regulation of in vitro somatic embryogenesis with emphasis on to the role of endogenous hormones, Rev. Bras. Fisiol. Veg. 13 (2001) 196-223, http://dx.doi.org/10.1590/S0103-31312001000200008.

[45] M. Vágner, Z. Vondráková, Z. Strnadová, J. Eder, I. Macháčková, Endogenous levels of plant growth hormones during early stages of somatic embryogenesis of Picea abies, Adv. Hortic. Sci. 12 (1998) 11-18.

[46] P. von Aderkas, M.A. Lelu, P. Label, Plant growth regulator levels during maturation of larch somatic embryos, Plant Physiol. Biochem. 39 (2001) 495-502, http://dx.doi.org/10.1016/S0981-9428(01)01271-2.

[47] P. von Aderkas, P. Label, M.-A. Lelu, Charcoal affects early development and hormonal concentrations of somatic embryos of hybrid larch, Tree Physiol. 22 (2002) 431-434, http://dx.doi.org/10.1093/treephys/22.6.431.

[48] M. Centeno, R. Rodríguez, B. Berros, A. Rodríguez, Endogenous hormonal content and somatic embryogenic capacity of Corylus avellana L. cotyledons, Plant Cell Rep. 17 (1997) 139-144, http://dx.doi.org/10.1007/s002990050367.

[49] L. Sáenz, A. Azpeitia, C. Oropeza, L.H. Jones, K. Fuchsova, L. Spichal, M. Strnad, Endogenous cytokinins in Cocos nucifera L. in vitro cultures obtained from plumular explants, Plant Cell Rep. 29 (2010) 1227-1234, http://dx.doi.org/10. 1007/s00299-010-0906-9.

[50] T. Gaspar, C. Kevers, C. Penel, H. Greppin, D.M. Reid, T.A. Thorpe, Plant hormones and plant growth regulators in plant tissue culture, In Vitr. Cell. Dev. Biol. - Plant. 32 (1996) 272-289, http://dx.doi.org/10.1007/BF02822700.

[51] L. Hao, L. Zhou, X. Xu, J. Cao, T. Xi, The role of salicylic acid and carrot embryogenic callus extracts in somatic embryogenesis of naked oat (Avena nuda), Plant Cell. Tissue Organ Cult. 85 (2006) 109-113.

[52] J.P. Luo, S.T. Jiang, L.J. Pan, Enhanced somatic embryogenesis by salicylic acid of Astragalus adsurgens Pall.: Relationship with $\mathrm{H}_{2} \mathrm{O}_{2}$ production and $\mathrm{H}_{2} \mathrm{O}_{2}$-metabolizing enzyme activities, Plant Sci. 161 (2001) 125-132, http:// dx.doi.org/10.1016/S0168-9452(01)00401-0.

[53] F. Quiroz-Figueroa, M. Méndez-Zeel, A. Larqué-Saavedra, V. Loyola-Vargas, Picomolar concentrations of salicylates induce cellular growth and enhance somatic embryogenesis in Coffea arabica tissue culture, Plant Cell Rep. 20 (2001) 679-684, http://dx.doi.org/10.1007/s002990100386.

[54] F.R. Quiroz-Figueroa, R. Rojas-Herrera, R.M. Galaz-Avalos, V.M. Loyola-Vargas, Embryo production through somatic embryogenesis can be used to study cell differentiation in plants, Plant Cell. Tissue Organ Cult. 86 (2006) 285-301. http://dx.doi.org/10.1007/s11240-006-9139-6.

[55] Y. Kanno, Y. Jikumaru, A. Hanada, E. Nambara, S.R. Abrams, Y. Kamiya, M. Seo, Comprehensive hormone profiling in developing Arabidopsis seeds: examination of the site of ABA biosynthesis, ABA transport and hormone interactions, Plant Cell Physiol. 51 (2010) 1988-2001, http://dx.doi.org/10. 1093/pcp/pcq158. 